LINKING OUTCOMES IN EDUCATION AND HEALTHCARE IMPROVEMENT

\section{A proposal: publication guidelines for healthcare improvement education reports}

\author{
D P Stevens, B Andersson-Gäre
}

The value of education reports lies in improving patient care outcomes

E ducational initiatives for health professionals to improve patient care are now an imperative for academic health settings in particular and all healthcare settings in general. This area of pedagogy requires an expert professoriate, and there is a developing literature on this topic. ${ }^{12}$ We propose the development of formal publication guidelines for this scholarly literature (box 1). This could contribute to its rigor and utility, and in turn, lead to better and more frequent publication of this literature in higher impact journals. Additional contributions from publication guidelines might also include improved research design and refined guidance for funding of such initiatives.

\section{ADAPTING EXISTING RESEARCH PUBLICATION GUIDELINES TO EDUCATION REPORTS}

Publication guidelines have been advanced with the aims of enhancing the rigor and utility of improvement research reports and defining clear expectations for authors, reviewers and editors. ${ }^{3-5}$ One such draft set of guidelines-now called SQUIRE (Standards for Quality Improvement Reporting Excellence)—was published in Quality and Safety in Health Care $^{56}$ and is undergoing a formal consensus process to sharpen the guidelines' wording, and to broaden their acceptance and use. We suggest there may be insights to be learned and efficiencies to be gained by extending the SQUIRE framework, with appropriate modifications, to reports on healthcare quality improvement (QI) education.

These draft publication guidelines for QI research ${ }^{5}$ employ the Introduction, Methods, Results and Discussion (IMRaD) format for reports of improvement studies and place special emphasis on the central place for experiential learning $^{7}$ in healthcare improvement research. An argument can be made that similar theory underlies education for healthcare improvement. Examples of guidelines that reflect the centrality of experiential learning in improvement research are: clear definition of the problem that needs improvement; the importance of clarity about the setting and context, and how they affect both the problem needing change and the strategy for its improvement; clarity in the description of the improvement intervention; and explicit attention to appropriate measurement, analysis and validity to show that the change embodied in the report is indeed an improvement. We propose that the underlying learning theory that is reflected in this format is similarly central to educational initiatives for healthcare improvement.

Box 1: Suggested outline of key components needed in publication guidelines for studies of education in healthcare improvement

(1) Employ the draft SQUIRE guidelines for healthcare improvement research, including use of the IMRaD format ${ }^{5}$

(2) Underlying theory of knowledge is anchored in experiential learning ${ }^{7}$

(3) The introduction contains a clear statement of what needs to be improved in the institution where the educational study is being done

(4) The methods reflect clarity and transparency, adequate detail, and qualitative and quantitative methods as needed for both the quality improvement initiative and the educational effort

(5) The components of the context for the initiative that are unique, and the opportunities to generalise to other settings are clearly set forth

(6) The results and discussion describe how the education initiative contributed to both the learner's knowledge and the improvement in the clinical care of patients or a population
We suggest that reports of education initiatives for healthcare improvement must explicitly extend their scope beyond learner-focused educational outcomes to the demonstration of improved patient care. Batalden and Davidoff have proposed that improving health professionals' learning and improving care are inevitably linked. ${ }^{8}$ They have advocated that healthcare needs better continual professional development to obtain continuously improved systems performance, which in turn are linked inextricably to better patient outcomes. Similarly, we argue that there is more to measurement of health professions' education than demonstration of changes in students' attitudes and acquisition of new knowledge, skills and competencies that are generally demonstrated by an academic examination. A parallel expectation should hold that learners can implement their learning about improvement in their care of patients. Of note, a recent critical review of scholarly publications that addressed healthcare professional education for quality improvement reported that only four of 39 scholarly educational reports could be shown to link educational and patient care outcomes. ${ }^{1}$

In the current issue of Quality and Safety in Health Care, Bechtold and colleagues (see page 422) provide an example of the application of the SQUIRE guidelines to an educational intervention. ${ }^{9}$ Their initiative modified the traditional morbidity and mortality conference to extend to methodical analysis and improvement of systems problems by resident trainees. Importantly, they showed the impact of these changes on both the trainees' knowledge and attitudes, and improvement in systems processes. They use the IMRaD format and reflect theory anchored in experiential learning. There was a demonstrated need for improvement in their institution. The methods are clear enough so that others could replicate what they did even though their organisational settings are unique. Importantly, they showed measured improvement in learners' knowledge and in the care of patients.

\section{HOW WILL WE KNOW THE GUIDELINES FOR EDUCATION} REPORTS ARE AN IMPROVEMENT? Publication guidelines will be deemed effective if they result in more and better education reports, if such reports are more frequently published in critical, high impact scholarly journals, and if such initiatives reflect more rigorous study and educational design. ${ }^{56}$ Such 
guidelines will increase the probability of publication if these reports are sufficiently transparent to provide descriptions of validated strategies that are more easily and widely adapted. Although the adaptation of publication guidelines for research to reports of education in improvement offers new opportunities for educational scholars, they bring the additional burden for authors to show the added value for both patient care and learning. On the other hand, editors, authors and reviewers must be mindful that onerous and inflexible application of such guidelines could suppress educational innovation.

We invite comments from Quality and Safety in Health Care readers on the potential use and advantages, as well as drawbacks, of additional publication guidelines for studies of education in improvement. In the interim, we invite authors to use the existing SQUIRE guidelines for reporting educational initiatives in healthcare improvement, as a further "road test" of the general utility of those guidelines.

\section{ACKNOWLEDGEMENTS}

The authors thank F Davidoff, D Neuhauser and P Batalden, for their review and thoughtful assistance in the preparation of this editorial.

Qual Saf Health Care 2007; 16:402-403.

doi: 10.1136/qshc.2007.025189

\section{Authors' affiliations}

D P Stevens, Quality Literature Program, Dartmouth Institute for Health Policy and Patient Care, Lebanon, New Hampshire, USA

Boel Andersson-Gäre, Linköping University; Futurum, Qulturum; Jönköping County Council, Sweden

Correspondence to: Dr D P Stevens, Quality

Literature Program, Dartmouth Institute for Health Policy and Patient Care, 30 Lafayette Street, Lebanon, New Hampshire 03766, USA;

David.P.Stevens@dartmouth.edu

Competing interests: None declared.

\section{REFERENCES}

1 Boonyasai RT, Windish DM, Chakraborti C, et al. Effectiveness of teaching quality improvement to clinicians. JAMA 2007;298:1023-37.

2 Batalden P, Davidoff F. Teaching quality improvement: the devil is in the details. JAMA 2007;298:1059-61

3 Moss F, Thomson RG. A new structure for quality improvement reports. Qual Saf Health Care 2004;13:6-7.

4 Speroff T, James BC, Nelson EC, et al. Guidelines for appraisal and publication of PDSA quality improvement. Qual Manag Health Care 2004;13:33-9.

5 Davidoff $F$, Batalden P. Toward stronger evidence on quality improvement. Draft publication guidelines: the beginning of a consensus project. Qual Saf Health Care 2005; 14:319-25.

6 Stevens DP. Why new guidelines for reporting improvement research? And why now? Qual Saf Health Care 2005; 14:314.

7 Kolb DA. Experiential learning. Experience as the source of learning and development. Englewood Cliffs, NJ: Prentice-Hall, 1984.

8 Batalden PB, Davidoff' $F$. What is "quality improvement" and how can it transform health care. Qual Saf Health Care 2007; 16:2-3.

9 Bechtold MK, Scott S, Nelson K, et al. Educational quality improvement report: outcomes from a revised morbidity and mortality format that emphasised patient safety. Qual Saf Health Care 2007;16:422-7.

\section{Quality Forum Abstracts}

Next year will see the publication of the Quality Forum 2008 abstracts published online with the April issue of Quality \& Safety in Health Care. They will be freely available online at http:// qshc.bmi.com and will be fully citable.

The Quality Forum is taking place on 23-25 April 2008, at the Le Palais des Congrès de Paris, Paris. For more information please visit http://www.quality.bmipg.com/. 